\title{
Dyslipidaemia, carbohydrate metabolism disorders and arterial hypertension detected in academic employees during examinations in occupational medicine
}

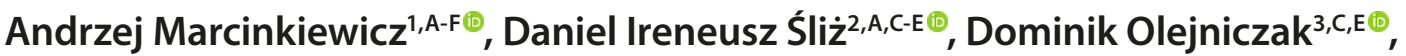

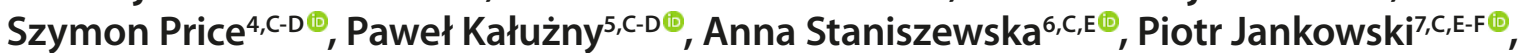 \\ Artur Mamcarz ${ }^{2, E-F} \oplus$, Jolanta Walusiak-Skorupa ${ }^{1, E-F} \oplus$, Wojciech Hanke ${ }^{5, C E-F \oplus}$ \\ 1 Department of Occupational Diseases and Environmental Health, Nofer Institute of Occupational Medicine, Łódź, Poland \\ 2 III Department of Internal Diseases and Cardiology, Medical University of Warsaw, Poland \\ ${ }^{3}$ Department of Public Health, Medical University of Warsaw, Poland \\ ${ }^{4}$ Department of Internal Medicine and Cardiology, Municipal Hospital in Olsztyn, Poland \\ ${ }^{5}$ Department of Environmental Epidemiology, Nofer Institute of Occupational Medicine, Łódź, Poland \\ ${ }^{6}$ Department of Experimental and Clinical Pharmacology, Medical University of Warsaw, \\ ${ }^{7}$ 1st Department of Cardiology, Interventional Electrocardiology and Hypertension, Institute of Cardiology, Jagiellonian \\ University Medical College, Jagiellonian University, Kraków, Poland \\ A - Research concept and design, B - Collection and/or assembly of data, C - Data analysis and interpretation, \\ $D$ - Writing the article, $E$ - Critical revision of the article, $F$ - Final approval of article
}

\begin{abstract}
Marcinkiewicz A, Śliż DI, Olejniczak D, Price S, Kałużny P, Staniszewska A, Jankowski P, Mamcarz A, Walusiak-Skorupa J, Hanke W. Dyslipidaemia, carbohydrate metabolism disorders and arterial hypertension detected in academic employees during examinations in occupational medicine. Ann Agric Environ Med. 2021; 28(2): 314-318. doi: 10.26444/aaem/128017
\end{abstract}

\section{Abstract}

Introduction. Many people have CVD risk factors without realising it and it is important to recognise the risk factors as soon as possible. Periodic examinations are a mandatory form of control for all employes in Poland. They provide an excellent opportunity to screen for the most common civilization diseases in the population.

Objective. The aim of this study is to evaluate the prevalence of dyslipidaemia, hyperglycaemia and hypertension among academics in a Polish university, and to compare the results between postdoctoral fellows and other academics.

Material and method. The study group were postdoctoral fellows ( $\mathrm{HAB} ; \mathrm{N}=135,53$ females) and other academics (NHAB; $\mathrm{N}=286,179$ females) over the age of 40 who reported for a periodic occupational medical check-up. Fasting blood samples were drawn, serum glucose, lipids and blood pressure (BP) were measured.

Results. The mean age was 56.7 (SD 9.8) in HAB and 49.8 (SD 8.1) in NHAB. Mean systolic BP and glycaemia were significantly higher in male HAB group than male NHAB (135.8 vs $130.9 \mathrm{mmHg}$ and $6.0 \mathrm{vs} 5.6 \mathrm{mmol} / \mathrm{l}$, respectively). The relationship in females was non-significant. The age-adjusted odds ratios (OR $[95 \% \mathrm{CI}]$ ) of having elevated low density lipoprotein cholesterol, total cholesterol, glucose and blood pressure in male HAB vs male NHAB were 0.61 [0.32. 1.16], $0.64[0.33,1.23]$, $1.52[0.80,2.88]$ and $2.11[0.88,5.23]$, and in female HAB vs female NHAB $-0.59[0.31,1.12], 0.64[0.32,1.26], 0.87[0.40,1.79]$ and $1.86[0.70,4.68]$, respectively.

Conclusions. Adequately planned occupational medicine examinations provide an opportunity to diagnose dyslipidaemia, hyperglycaemia, or high BP in all groups of employees, including highly educated academics.

I Key words

hypertension, dyslipidaemia, early detection, prophylactic examinations, hyperglicaemia

\section{INTRODUCTION}

One of the paradigms in occupational medicine is that better health awareness and a resultant reduction in the risk of developing chronic diseases of civilization goes in parallel with a higher level of education. From this point of view, academics employed at a university are expected to be especially conscious of health hazards and are therefore rarely the subject of specific research. This study is one of the first to present the basic health parameters in this group of patients.

Address for correspondence: Andrzej Marcinkiewicz, Nofer Institute of Occupational Medicine, Łódź, Poland

E-mail: and.mar@interia.pl

Received: 01.07.2020; accepted: 01.10.2020; first published: 13.10.2020
It assesses the homogeneity of this group by comparing the parameters of employees with a postdoctoral fellowship title (who should be the most health-aware according to the above-mentioned paradigm) with other academics with a university degree, i.e. teaching assistants, researchers and lecturers.

In the general population, cardiovascular disease (CVD) causes over 4 million deaths in Europe each year [1]. Dyslipidaemia, diabetes and hypertension are all major controllable factors responsible for these deaths [2]. Reducing the prevalence of these risk factors is the main reason for the decline in CVD-related mortality [2]. Treatment of dyslipidaemia can reduce the risk of heart disease by as much as $30 \%$ over a 5 -year period [3]. It is therefore essential 
to detect these disorders as soon as possible in order to initiate treatment.

A large epidemiological study in Poland revealed that over $60 \%$ of adults have hypercholesterolaemia, and $60 \%$ of them are unaware of the condition. A further $20 \%$ are aware, but are not treated, while only $10.9 \%$ are being effectively treated [4]. The highest prevalence was observed in the age group 40-59. The prevalence of diabetes in Poland is also high at $6.97 \%$ (diagnosed and undiagnosed cases) [5], with over a quarter of the patients with diabetes being unaware that they have the disease [6]. Similarly, the prevalence of arterial hypertension is also high at $42.7 \%$, with an awareness level of $59.3 \%$ [7]. Only $23 \%$ of cases are adequately controlled. The prevalence has also increased by $12 \%$ over 10 years.

The above data indicate an urgent need to increase the detection rates of CVD risk factors in order to apply effective treatment and prevention methods. One way of achieving this could be through regular employee obligatory checkups in institutions. In Poland over 5 million such visits are registered every year [8], offering an excellent opportunity to screen for CVD risk factors.

\section{OBJECTIVE}

The aim of the study was to evaluate the prevalence of hypertension, hyperglycaemia and dyslipidaemia in a Polish university by analysing the differences in CVD risk factors between postdoctoral fellows (pol. doktor habilitowany. i.e. doctors after habilitation) and employees with MSc or a PhD title. An attempted was made to assess whether obtaining a postdoctoral fellowship is a protective factor in a university setting.

\section{MATERIALS AND METHOD}

The study was conducted in 2018 on all employees of one of the universities in Łódż, central Poland, who reported for obligatory medical check-ups based on referrals from the employer. Two groups of subjects were considered: postdoctoral fellows with habilitation (HAB) and others with any university degree (NHAB). All eligible employees were assessed, but the age cut-off of $\geq 40$ years was introduced in order to obtain comparable groups of subjects (otherwise, the HAB group would not have a representative number of subjects aged $<40$, because achieving habilitation below 40 year of age is infrequent). In addition to the standard procedures required by employee's check-ups, fasting blood samples were drawn and analysed in a certified laboratory. Arterial blood pressure, lipidogram, and glucose were measured as health outcomes for the study. LDL concentration was calculated with the Friedewald formula. Reference ranges were established according to current Polish guidelines [9].

The initial number of participants was 850 ; however, after excluding subjects under the age of 40 , the final number of participants was 421 (55.1\% female). For further analysis, male and female participants were discussed separately, due to different normative ranges of the health outcomes and different incidence of CVD risk factors in both genders. Subsequently, both groups were divided into academic workers without habilitation (MSc or PhD only, NHAB) and habilitated postdoctoral fellows (HAB).
Data analysis was performed with the use of Statistica (version 13) and R (version 3.5) software. For crude characterisation of the study population, mean values of the health outcomes in the habilitated (HAB) group and the nonhabilitated (NHAB) group were calculated and compared by the t-test $(\mathrm{P}<0.05$ was used as an approximate indicator of difference, strict statistical criteria of normality and equality of variances were not met). Frequencies of non-normative outcomes in both groups ( $\mathrm{HAB} / \mathrm{NHAB})$ were compared by the Chi-squared test, or Fisher's exact test (for HDL in female group). Crude and age-adjusted odds ratios (OR) with 95\% confidence intervals [95\% CI] for nonnormative outcome (coded as '1') against outcome in the normative range (taken as reference, coded as "0"), in HAB relative to NHAB group, were obtained from logistic regression with subject group as the main explanatory variable (with $\mathrm{NHAB}$ group taken as reference, and coded as ' 0 '), and age (in years) included as additional explanatory variable.

The study protocol was approved by the local Bioethical Committee at the Nofer Institute of Occupational Medicine in Łódż (Decision No. 04/2015 of 18 February 2015).

\section{RESULTS}

The study group consisted of academics aged $>40$ years, 189 males (mean age - 54.4, SD 10.4) and 232 females (mean age -49.5 , SD 7.3). The NHAB group was younger (mean age 49.88, SD 8.1) and included 286 subjects - 107 males (mean age -51 , SD 9.2) and 179 females (mean age -49 ., SD 7.3). The HAB group (mean age - 56.7, SD 9.8) included 135 subjects - 82 males (mean age - 8.9, SD 10.2) and 53 females (mean age -53.3 , SD 8.2). Table 1 presents the mean values with SD of all the parameters in both groups in males and females. Among males, the glucose levels and systolic blood pressure were noticeably higherint the more advanced academic career level (HAB group). Among females, the glucose level was not noticeably changed, but there was some increase in systolic blood pressure in the HAB group.

The number of subjects with nonnormative values of total cholesterol (TC), LDL, HDL, glucose and blood pressure are shown in Tables 2 and 3 for ales and females, respectively. While there are noticeable changes in frequencies and crude odds ratios for non-normative values, in the $\mathrm{HAB}$ relative to NHAB group. These were mostly attributed to age difference between the groups, because confidence intervals for ageadjusted ORs all embrace the value of 1 .

\section{DISCUSSION}

Postdoctoral fellows are academics who have a $\mathrm{PhD}$ title and have completed the habilitation process and are fully independent researchers. This is formal proof of a higher degree of education and an advanced career in research. Doctors after habilitation often also have the title 'professor' and often occupy a high post, such as chair of a department.

Hypertension. Systolic arterial blood pressure was significantly higher in the male $\mathrm{HAB}$ group than in the male NHAB group (the relationship in females being similar, but non-significant). In the male and female HAB group, the number of participants with abnormal blood pressure, as well 
Table 1. Values of total cholesterol, low density lipoprotein, high density lipoprotein, glucose and blood pressure systolic (BP.s) and diastolic (BP.d) expressed as mean with SD and P-values for comparison of the means in NHAB (lower grade) and HAB (higher grade) academic group, separately in males and females

\begin{tabular}{|c|c|c|c|c|c|c|}
\hline & \multicolumn{3}{|c|}{ Male } & \multicolumn{3}{|c|}{ Female } \\
\hline & NHAB (107) & HAB (82) & & NHAB (179) & HAB (53) & \\
\hline & mean (SD) & mean (SD) & $\mathrm{P}$ & mean (SD) & mean (SD) & $\mathrm{P}$ \\
\hline $\mathrm{TC}(\mathrm{mmol} / \mathrm{l})$ & $5.39(1)$ & $5.21(1.2)$ & 0.248 & $5.49(1.1)$ & $5.48(1.1)$ & 0.987 \\
\hline $\mathrm{LDL}(\mathrm{mmol} / \mathrm{l})$ & $3.34(0.9)$ & $3.17(1)$ & 0.219 & $3.27(1)$ & $3.17(1)$ & 0.498 \\
\hline $\mathrm{HDL}(\mathrm{mmol} / \mathrm{l})$ & $1.40(0.3)$ & $1.39(0.4)$ & 0.918 & $1.70(0.4)$ & $1.82(0.4)$ & 0.098 \\
\hline Glucose (mmol/l) & $5.59(1)$ & $6.02(1.5)$ & 0.022 & $5.26(0.6)$ & $5.25(0.8)$ & 0.944 \\
\hline BP.s (mmHg) & $130.9(14.5)$ & $135.8(13.9)$ & 0.020 & $123.7(14.8)$ & $127.3(15.3)$ & 0.118 \\
\hline BP.d (mmHg) & $80.9(9.1)$ & $82.8(7.6)$ & 0.116 & $77.2(9.0)$ & $78.4(10.1)$ & 0.394 \\
\hline
\end{tabular}

BP.d - blood pressure diastoli; BP.s - blood pressure systoli; HDL - high density lipoprotein; HAB - postdoctoral fellows (pol. doktor habilitowany, i.e. doctors after habilitation); LDL - low density lipoprotein; NHAB - academics with MSc or a PhD; TC - total cholesterol.

Table 2. Number and percentage of males with nonnormative glucose, lipid levels or blood pressure in both groups, with P-value for equality of proportion of non-normative value, and the crude and age-adjusted (Adj) odds ratios (OR) for falling within the nonnormative range of the given parameter for HAB vs NHAB group, with $95 \%$ Confidence Intervals $(95 \% \mathrm{Cl})$

\begin{tabular}{lccccc}
\hline & NHAB (107) & HAB (82) & Crude OR [95\% Cl] & Adj OR [95\% Cl] \\
\hline $\mathrm{NC}>4,9 \mathrm{mmol} / \mathrm{l}$ & $\mathrm{N}(\%)$ & $42(51.2)$ & 0.013 & $0.45[0.25,0.81]$ & $0.64[0.33,1.23]$ \\
\hline $\mathrm{LDL}>3 \mathrm{mmol} / \mathrm{l}$ & $75(70.1)$ & $37(45.1)$ & 0.008 & $0.43[0.24,0.78]$ & $0.61[0.32,1.16]$ \\
\hline $\mathrm{HDL}<1 \mathrm{mmol} / \mathrm{l}$ & $70(65.4)$ & $68(82.9)$ & 0.709 & $0.79[0.36,1.75]$ & $0.90[0.38,2.15]$ \\
\hline Glucose $>5.6 \mathrm{mmol} / \mathrm{l}$ & $92(86.0)$ & $48(58.5)$ & 0.013 & $2.18[1.21,3.93]$ & $1.52[0.80,2.88]$ \\
\hline $\mathrm{BP} \geq 140 / 90 \mathrm{mmHg}$ & $42(39.3)$ & $17(21.0)$ & 0.066 & $2.32[1.03,5.41]$ & $2.11[0.88,5.23]$ \\
\hline
\end{tabular}

$\mathrm{BP}$ - blood pressure; HDL - high density lipoprotein; $\mathrm{HAB}$ - postdoctoral fellows (pol. doktor habilitowany, i.e. doctors after habilitation); LDL - low density lipoprotein; NHAB - academics with MSc or a PhD; TC - total cholesterol.

Table 3. Number and percentage of females with nonnormative glucose, lipid levels or blood pressure in both groups, with P-value for equality of proportion of nonnormative values and the crude and age-adjusted (Adj) odds ratios (OR) for falling within the nonnormative range of the given parameter for HAB vs NHAB group, with $95 \%$ Confidence Intervals (95Cl)

\begin{tabular}{lccccc}
\hline & NHAB (179) & HAB (53) & Crude OR [95\% Cl] & Adj OR [95\% Cl] \\
\hline $\mathrm{TC}>4.9 \mathrm{mmol} / \mathrm{l}$ & $\mathrm{N}(\%)$ & $34(64.2)$ & 0.539 & $0.77[0.40,1.47]$ & $0.64[0.32,1.26]$ \\
\hline $\mathrm{LDL}>3 \mathrm{mmol} / \mathrm{l}$ & $125(69.8)$ & $27(50.9)$ & 0.324 & $0.7[0.37,1.29]$ & $0.59[0.31,1.12]$ \\
\hline $\mathrm{HDL}<1.2 \mathrm{mmol} / \mathrm{l}$ & $107(59.8)$ & $1(1.9)$ & 0.130 & $5.1[0.02,1.51]$ & $3.74[0.70,69.23]$ \\
\hline Glucose $>5.6 \mathrm{mmol} / \mathrm{l}$ & $16(8.9)$ & $13(24.5)$ & 1 & $1.06[0.51,2.17]$ & $0.87[0.40,1.79]$ \\
\hline $\mathrm{BP} \geq 140 / 90 \mathrm{mmHg}$ & $42(23.5)$ & $9(17.0)$ & 0.089 & $2.11[0.88,5.23]$ & $1.86[0.70,4.68]$ \\
\hline
\end{tabular}

$\mathrm{BP}$ - blood pressure; HDL - high density lipoprotein; $\mathrm{HAB}$ - postdoctoral fellows (pol. doktor habilitowany, i.e. doctors after habilitation); LDL - low density lipoprotein; NHAB - academics with MSc or a PhD; TC - total cholesterol.

as the age adjusted OR, were both more than twice as high as in the NHAB group. There may be several explanations for this difference. Firstly, the HAB group had a higher mean age and the WOBASZ study demonstrated that SBP rises with age until about the age of 70 [10]. Secondly, achieving the degree of a postdoctoral fellow may be in itself stressful due to the highly competitive environment and challenging work. Furthermore, postdoctoral fellows often occupy posts of high responsibility in their workplaces which may lead to higher work strain, a known risk factor of hypertension, especially among older employees [11]. The data from the very few studies conducted on work stress levels in academics is inconclusive, whereas research in other workers shows that older age has both benefits and drawbacks in terms of stress regulation (e.g. better emotional regulation, but higher strain) [12].

Carbohydrate metabolism disorders. The male HAB group had significantly higher blood glucose levels than NHAB, and their glucose levels were more frequently outside the normal range $(<5.6 \mathrm{mmol} / \mathrm{l})$. No such relationship was observed in the females, perhaps again due to the smaller age gap. The risk of elevated glucose levels in the HAB group in males was also higher after age adjustment, whereas the age-adjusted OR in females was non-significant in HAB and NHAB.

The prevalence of impaired fasting glucose in both male groups was relatively high. Polish data on the precise age distribution of impaired fasting glucose (IFG) is lacking. In a metaanalysis of papers on IFG in Europe, the authors report a prevalence of IFG of $10.6 \%$ in males aged $30-65$ and only $8.9 \%$ in those aged $66+[13]$. The results obtained in this study seem exceptionally high. A possible lack of compliance among senior academic staff (i.e. not fasting before the blood had been drawn) may also have been an important factor.

The study was conducted on highly educated individuals on the academic staff of a university, many of whom therefore may have considered that they did not need medical check-ups and 
ignored doctors' instructions. Another reason may be that most academic work involves considerable sedentary time, which is an important risk factor of insulin resistance [14].

Dyslipidaemia. The percentage of patients with TC $>4.9$ $\mathrm{mmol} / \mathrm{l}$ was slightly lower in this study then in the Polish population observed in the NATPOL study, where this percentage for patients aged $40-59$ was $72 \%$. The percentage was lower in the older age group (60-79) at 59\%[4]. In the light of these data, surprisingly few patients in the male HAB group had TC $>4.9 \mathrm{mmol} / 1$ (51\%), significantly fewer than in the NHAB group. A possible explanation may be that more of them could have been be aware of having dyslipidaemia and were already receiving adequate treatment. This is supported by data from the Swiss FIRE project which demonstrated that the prevalence of abnormal lipid profiles in males aged 55-64 is only slightly higher than in males aged 45-54 [15]. The prevalence of dyslipidaemia treated with drugs is, however, was almost twice as high.

The difference between $\mathrm{NHAB}$ and $\mathrm{HAB}$ is even more pronounced in terms of LDL, with only $45 \%$ in the male $\mathrm{HAB}$ group presenting levels over $3 \mathrm{mmol} / \mathrm{l}$, compared to $65 \%$ in $\mathrm{NHAB}$, and $75 \%$ in the NATPOL study. The results in females were similar across the HAB and NHAB groups, but also lower than in the NATPOL population. This is in accordance with a recent study demonstrating a lower prevalence of dyslipidaemia in individuals with higher education [16].

The age distribution of the prevalence of dyslipidaemia in adults varies considerably according to different studies in different countries $[4,17,18]$; the diagnostic criteria also vary, as do the age brackets for the presented age groups, which makes age standardization difficult to perform and interpret. The raw OR of having an abnormal TC level was as low as 0.45 for the male HAB group. This is unlikely to be attributed solely to the age gap, given the above-mentioned results from the FIRE project. Thus, other reasons could be considered, such asdifferences in lifestyle or access to healthcare. A possible explanation might be a potentially higher income level achieved by the HAB group, and therefore better access to private healthcare on a regular basis, receiving more and/or better preventive advice and treatment. The higher social status and wider social connections, among others with medical doctors, which the HAB group members may have, may also improve access to high quality healthcare. This situation could be due to the relatively poor quality of primary care in Poland [19]. It might also be that the older workers in the HAB group more often work part-time and have more free time for a healthy lifestyle, but this was not analysed in the presented study.

Furthermore, members of the HAB group are likely to be highly motivated and ambitious, given their advanced career, and therefore may also be more motivated to care for their own health.

\section{CONCLUSIONS}

A more advanced academic career, defined as achieving the title of a postdoctoral fellow, is not the main factor determining the analysed health status parameters, but it does appear to be in a way protective against abnormal LDL and TC. Conversely, it may be associated with an increased risk of elevated blood pressure and hyperglycaemia.
Further studies are required to determine the the exact causes of the described relationships and their clinical importance, and whether they would influence such key parameters as mortality or risk of CVD. Adequately planned occupational medicine examinations provide an opportunity to diagnose dyslipidaemia, hyperglycaemia, or high blood pressure, and offer the opportunity for counselling about CVD risk factors in all groups of employees, including highly educated academics.

\section{REFERENCES}

1. Mach F, Baigent C, Catapano AL, Koskinas KC, Casula M, Badimon L, et al. 2019 ESC/EAS Guidelines for the management of dyslipidaemias: lipid modification to reduce cardiovascular risk: The Task Force for the management of dyslipidaemias of the European Society of Cardiology (ESC) and European Atherosclerosis Society (EAS). Eur Heart J [Internet]. 2019; 41: 111-88. Available from: https://doi.org/10.1093/ eurheartj/ehz455

2. Wijeysundera HC, Machado M, Farahati F, Wang X, Witteman W, van der Velde $\mathrm{G}$, et al. Association of temporal trends in risk factors and treatment uptake with coronary heart disease mortality, 1994-2005. JAMA. United States; 2010; 303: 1841-7.

3. Goff DC Jr, Bertoni AG, Kramer H, Bonds D, Blumenthal RS, Tsai MY, et al. Dyslipidemia Prevalence, Treatment, and Control in the Multi-Ethnic Study of Atherosclerosis (MESA). Circulation [Internet]. American Heart Association; 2006; 113: 647-56. Available from: https:// doi.org/10.1161/ CIRCULATIONAHA.105.552737

4. Yu OHY, Suissa S. Identifying Causes for Excess Mortality in Patients With Diabetes: Closer but Not There Yet. Diabetes Care [Internet]. 2016; 39: 1851 LP - 1853. Available from: http://care.diabetesjournals. org/content/39/11/1851.abstract

5. Zdrojewski T, Solnica B, Cybulska B, Bandosz P, Rutkowski M, Stokwiszewski J, et al. Prevalence of lipid abnormalities in Poland. The NATPOL 2011 survey. Kardiol Pol. Poland; 2016; 74: 213-23.

6. Topor-Madry R, Wojtyniak B, Strojek K, Rutkowski D, Bogusławski S, Ignaszewska-Wyrzykowska A, et al. Prevalence of diabetes in Poland: a combined analysis of national databases. Diabet Med. England; 2019; 36: 1209-16.

7. Rutkowski M, Bandosz P, Czupryniak L, Gaciong Z, Solnica B, JasielWojculewicz H, et al. Prevalence of diabetes and impaired fasting glucose in Poland - the NATPOL 2011 Study. Diabet Med. England; 2014; 31: 1568-71.

8. Małyszko J, Mastej M, Banach M, Tykarski A, Narkiewicz K, Hoffman $\mathrm{P}$, et al. Do we know more about hypertension in Poland after the May Measurement Month 2017? - Europe. Eur Hear J Suppl [Internet]. 2019; 21: D97-100. Available from: https://doi.org/10.1093/eurheartj/suz067

9. Marcinkiewicz A. Zasoby i działalność jednostek służby medycyny pracy w Polsce. Analiza obligatoryjnej sprawozdawczości za lata 20142018. Med Pr. 2020; 71.

10. Czerwińska K, Gać P, Poręba R, Mazur G, Pawlas K. Cardiac and vascular disorders as para-occupational diseases - a Polish perspective. Ann Agric Environ Med [Internet]. 2020; Available from: http://dx.doi. org/10.26444/aaem/122259

11. Krzowski B, Płatek AE, Szymański FM, Ryś A, Semczuk-Kaczmarek K, Adamkiewicz K, et al. Epidemiology of dyslipidaemia in professional drivers: results of RACER-ABPM (Risk of Adverse Cardiovascular Events among professional dRivers in Poland - Ambulatory Blood Pressure Monitoring) study. Kardiol Pol. Poland; 2018; 76: 396-400.

12. Mirmohammadi SJ, Taheri M, Mehrparvar AH, Heydari M, Saadati Kanafi A, Mostaghaci M. Occupational stress and cardiovascular risk factors in high-ranking government officials and office workers. Iran Red Crescent Med J [Internet]. 2014/08/01. Kowsar; 2014; 16: e11747e11747. Available from: https://pubmed.ncbi.nlm.nih.gov/25389469

13. Ofori SN, Obosi J. Prevalence of hypertension among office workers in a multi-national company in the Niger-Delta with the 2017 American College of Cardiology/American Heart Association Blood Pressure Guidelines. Prev Med reports [Internet]. Elsevier; 2019; 15: 100899. Available from: https://pubmed.ncbi.nlm.nih.gov/31193562

14. Szymański FM, Barylski M, Cybulska B, Wożakowska-Kapłon B, Krasiński Z, Mamcarz A, et al. Recommendation for the management of dyslipidemia in Poland - Third Declaration of Sopot. Interdisciplinary Expert Position Statement endorsed by the Polish Cardiac Society 
Working Group on Cardiovascular Pharmacotherapy. Cardiol J. Poland; 2018; 25: 655-65.

15. Piotrowski W, Waskiewicz A, Cicha-Mikolajczyk A. Global cardiovascular mortality risk in the adult Polish population: prospective assessment of the cohorts studied in multicentre national WOBASZ and WOBASZ Senior studies. Kardiol Pol. Poland; 2016; 74: 262-73.

16. Tsutsumi A, Kayaba K, Tsutsumi K, Igarashi M. Association between job strain and prevalence of hypertension: a cross sectional analysis in a Japanese working population with a wide range of occupations: the Jichi Medical School cohort study. Occup Environ Med [Internet]. 2001; 58: 367 LP - 373. Available from: http://oem.bmj.com/content/58/6/367. abstract

17. Radi S, Lang T, Lauwers-Cancès V, Diène E, Chatellier G, Larabi L, et al. Job constraints and arterial hypertension: different effects in men and women: the IHPAF II case control study. Occup Environ Med [Internet]. 2005; 62: 711 LP-717. Available from: http://oem.bmj.com/ content/62/10/711.abstract

18. Cornelia R, Stefan K, Markus T, Guido H. Age and work-related stress: a review and meta-analysis. Guido Hertel Annet H. de Lange, Jürgen Deller BIJM van der H, editor. J Manag Psychol [Internet]. Emerald Group Publishing Limited; 2013; 28: 781-804. Available from: https:// doi.org/10.1108/JMP-07-2013-0251

19. Fishta A, Backé E-M. Psychosocial stress at work and cardiovascular diseases: an overview of systematic reviews. Int Arch Occup Environ Health [Internet]. 2015/02/17. Springer Berlin Heidelberg; 2015; 88: 997-1014. Available from: https://pubmed.ncbi.nlm.nih.gov/25687981

20. Eades CE, France EF, Evans JMM. Prevalence of impaired glucose regulation in Europe: a meta-analysis. Eur J Public Health [Internet]. 2016; 26: 699-706. Available from: https://doi.org/10.1093/eurpub/ ckw085

21. Kim KS, Kim SJ, Kim S, Choi D-W, Ju YJ, Park E-C. Association of self-reported sedentary time with insulin resistance among Korean adults without diabetes mellitus: a cross-sectional study. BMC Public Health [Internet]. 2018; 18: 1335. Available from: https://doi.org/10.1186/ s12889-018-6237-4

22. Wilmot EG, Edwardson CL, Achana FA, Davies MJ, Gorely T, Gray LJ, et al. Sedentary time in adults and the association with diabetes, cardiovascular disease and death: systematic review and meta-analysis. Diabetologia. Germany; 2012; 55: 2895-905.

23. Kivimäki M, Virtanen M, Kawachi I, Nyberg ST, Alfredsson L, Batty $\mathrm{GD}$, et al. Long working hours, socioeconomic status, and the risk of incident type 2 diabetes: a meta-analysis of published and unpublished data from 222120 individuals. lancet Diabetes Endocrinol [Internet]. 2014/09/25. The Lancet, Diabetes \& Endocrinology; 2015; 3: 27-34. Available from: https://pubmed.ncbi.nlm.nih.gov/25262544

24. Weinhold KR, Miller CK, Marrero DG, Nagaraja HN, Focht BC, Gascon GM. A Randomized Controlled Trial Translating the Diabetes Prevention Program to a University Worksite, Ohio, 2012-2014. Prev Chronic Dis [Internet]. Centers for Disease Control and Prevention; 2015; 12: E210-E210. Available from: https://pubmed.ncbi.nlm.nih. gov/26605710

25. Zellweger U, Bopp M, Holzer BM, Djalali S, Kaplan V. Prevalence of chronic medical conditions in Switzerland: exploring estimates validity by comparing complementary data sources. BMC Public Health [Internet]. 2014; 14: 1157. Available from: https://doi.org/10.1186/14712458-14-1157

26. Cho SMJ, Lee HJ, Shim JS, Song BM, Kim HC. Associations between age and dyslipidemia are differed by education level: The Cardiovascular and Metabolic Diseases Etiology Research Center (CMERC) cohort. Lipids Health Dis [Internet]. 2020; 19: 12. Available from: https://doi. org/10.1186/s12944-020-1189-y

27. Ha KH, Kwon H-S, Kim DJ. Epidemiologic Characteristics of Dyslipidemia in Korea. J Lipid Atheroscler [Internet]. Korean Society of Lipidology and Atherosclerosis; 2015; 4: 93-9. Available from: https:// doi.org/10.12997/jla.2015.4.2.93

28. Chmiel C, Bhend H, Senn O, Zoller M, Rosemann T. The FIRE project: a milestone for research in primary care in Switzerland. Swiss Med Wkly. Switzerland; 2011; 140: w13142.

29. Krztoń-Królewiecka A, Oleszczyk M, Schäfer WLA, Boerma WG, Windak A. Quality of primary health care in Poland from the perspective of the physicians providing it. BMC Fam Pract [Internet]. BioMed Central; 2016; 17: 151. Available from: https://pubmed.ncbi. nlm.nih.gov/27809809 